Christian Witt

\title{
Innerprotestantische Ökumene und Bekenntnis
}

\author{
Zur Frage der Augsburger Konfessionsverwandtschaft im Reich \\ bis 1648
}

\section{Konzeptionelle Vorüberlegungen}

Historisch-theologisch betrachtet, wird der betont affirmative Bezug auf einen konfessionellen Text publizistisch dann besonders augenfällig, wenn dieser Text nicht nur als integraler Bestandteil der eigenen theologischen Tradition wahrgenommen wird, sondern darüber hinaus als ein maßgeblicher Referenzpunkt oder gar ein Artikulationsmedium des eigenen, konfessionell-religiös spezifischen Wahrheitsbegriffs, den es auch institutionell aufrechtzuerhalten und angesichts konkurrierender Wahrheitsansprüche durchzusetzen gilt. Im frühneuzeitlichen Werden der Konfessionen kommt einem solchen Referenzpunkt eine eminent institutionsstabilisierende Funktion zu. Unter diesen Voraussetzungen ist jener affirmative Bezug selbst aus der Perspektive konfessionell anders geprägter, bezüglich des religiösen Wahrheitsbegriffs konkurrierender Personen, Institutionen oder Theologien zwar nicht immer verständlich oder gar akzeptabel, aber doch als diskursives Phänomen einigermaßen durchschaubar und damit nachvollziehbar. Wird der affirmative theologische Bezug in seiner religiös profilstiftenden und institutionell stabilisierenden Qualität dann auch noch durch rechtliche Festsetzungen flankiert, die den betreffenden Referenztext zum juristisch-normativ und entsprechend öffentlich legitimierten Identifikationspunkt der eigenen konfessionell-religiösen Gruppe erheben, werden positiv-bejahende Wahrnehmung und traditional-identifikatorische Geltendmachung geradezu selbstverständlich und gegebenenfalls juristisch notwendig.

Das ist freilich institutionentheoretisch begründbar: Die das spannungsreiche Werden der Konfessionen begleitenden und sich auch in der Bekenntnisbildung niederschlagenden Institutionalisierungsprozesse lassen sich im Sinne sozialer Ordnungsleistungen verstehen als Mechanismen der Durchsetzung von Ordnungsansprüchen und -behauptungen und damit als Stabilisierungsleistungen. Dahinter steht die Annahme, dass „das Institutionelle an einer Ordnung [...] 
die symbolische Verkörperung ihrer Geltungsansprüche“1 ist. In diesem Sinne wären dann die sich gesellschaftlich sowie politisch-rechtlich etablierenden und sich theologisch-institutionell in gegenseitiger Abgrenzung profilierenden Konfessionskirchen Organisationsformen, „,in denen die Sichtbarkeit der Ordnung in den Mittelpunkt gerückt wurde“ ${ }^{\text {2 }}$ - beispielsweise mittels der Produkte der Bekenntnisbildung. Und unter diesen nimmt die Confessio Augustana unstrittig einen besonderen Rang ein; sie stellt als Teil jener Institutionalisierungsprozesse eine - gemessen an ihrer geschichtlichen Wirkmacht qua affirmativer und diskursdynamisierender Rezeption - erhebliche Ordnungsleistung dar. Die große Bedeutung der protestantischen Bekenntnisschriften im Allgemeinen, der Confessio Augustana als spezifischer kirchlicher Ordnungs- und Stabilisierungsleistungen im Besonderen spiegelt sich wiederum in den historisch feststellbaren Transzendierungsbestrebungen, durch die „faktische und normative Geltungsbehauptungen“ bereitgestellt werden, „die das je gelten Sollende von den Entstehungszusammenhängen und ursprünglichen Veranlassungen abheben und es ermöglichen, daß auch hier Geltung und Genese nicht in eins fallen“3. Das Bekenntnis verdankt sich demnach zwar einem klar bestimmbaren geschichtlichen Anlass, transportiert aber eine von diesem Anlass letztlich unbedingte übergeschichtliche, nur situativ in Lehrsätze überführte Wahrheit, deren sich herauskristallisierende, aus der werdenden und sich schnell festigenden konfessionellen Pluralität resultierende dogmatische Partikularität gerade nicht Teil des mit ihr artikulierten Geltungsanspruchs ist.

Die durch das Augsburger Bekenntnis und seine affirmative Rezeption geleistete institutionelle Ordnungsstabilisierung durch symbolische Verkörperung faktischer und normativer Geltungsbehauptungen reformatorischer Theologie äußert sich nun maßgeblich durch die Reklamation der Augsburger Konfessionsverwandtschaft. Dabei handelt es sich - weiterhin institutionentheoretisch gesprochen - um eine Leitidee: „Die Symbolisierungsleistung des Institutionellen drückt sich auch in einer ,Leitidee، aus, einer als gültig empfundenen Bestimmung dessen, was der ,Staat‘, die römische Kirche, ,die Kunst` etc. jeweils sein

1 Karl-Siegbert Rehberg, Institutionen als symbolische Ordnungen. Leitfragen und Grundkategorien zur Theorie und Analyse institutioneller Mechanismen, in: ders., Symbolische Ordnungen. Beiträge zu einer soziologischen Theorie der Institutionen, hg.v. Hans Vorländer, Baden-Baden 2014, 43-83, hier: 55.

2 Karl-Siegbert Rehberg, Die ,Öffentlichkeit‘ der Institutionen. Grundbegriffliche Überlegungen im Rahmen der Theorie und Analyse institutioneller Mechanismen, in: ders., Symbolische Ordnungen, $85-117$, hier: 85.

3 Rehberg, Institutionen als symbolische Ordnungen, 62. 
wollen“4 . In und mit dem Begriff der Augsburger Konfessionsverwandtschaft wird nun sowohl theologisch wie - erstmals im Umfeld des Frankfurter Anstands und regelmäßig spätestens seit dem Augsburger Religionsfrieden von 1555 - auch reichsrechtlich nicht zuletzt eine als gültig empfundene Bestimmung dessen zum Ausdruck gebracht, was reformatorischerseits wahre Kirche sein soll; der Begriff benennt präzise den Ort, an dem gültig festgehalten ist, wie die rechte Kirche beschaffen ist, welche Lehre sie traditionsgestützt vertritt und worauf sie dogmatisch-theologisch basiert. Auch darin liegt das offenkundig schon von den Zeitgenossen wahrgenommene Potential des mit jener Leitidee artikulierten affirmativen Bezugs auf die Confessio Augustana; der dort in Lehre überführten Wahrheit weiß man sich verwandt.

Allerdings handelt es sich bei Leitideen wie im Falle der Augsburger Konfessionsverwandtschaft in analytischer Perspektivierung keineswegs um singuläre oder homogene Phänomene, ganz im Gegenteil: Zumeist beinhalten sie unausgesprochen eine ganze Vielfalt von Vorstellungen oder konfligierender Ideen, was sie eigentlich meinen und auf wen oder was sie sich beziehen. „Und jede durchgesetzte Leitidee zieht ihren Erfolg aus der (temporären) Herausgehobenheit aus einem Komplex oftmals unvereinbarer Orientierungsmöglichkeiten. Eine Leitidee ist eine Synthese von Widersprüchlichem und verleugnet zugleich die Mehrzahl der in ihr spannungsreich verarbeiteten und der mit ihr konkurrierenden Sinnsetzungen und Ordnungsentwürfe. Jedoch ist ihre Geltung nie unbestritten und von den unterschiedlichen Interessen von Trägerschichten abhängig“5.

In bestimmten historisch-theologischen Konstellationen oder geschichtlichen Situationen offenbaren derartige scheinbar Selbstverständliches artikulierende und Eindeutigkeit suggerierende Semantiken den in der entsprechenden Leitidee verarbeiteten Spannungsreichtum und damit ihre konfliktträchtige Mehrdeutigkeit. Die sich dann konkurrenzbedingt entladenden Ansprüche auf die strittig gewordene Deutungshoheit konterkarieren die behauptete Selbstverständlichkeit, die reklamierte Eindeutigkeit und nicht zuletzt die beanspruchte Legitimität der betreffenden Selbstzuschreibung. Die angesichts der drohenden Einbußen aufkommenden religiös-konfessionellen Infragestellungen entwickeln nicht selten eine existentielle Tragweite, vor allem im Falle der inhaltlichen und institutionellen Verquickung mit Fragen der rechtlichen Ordnung. Die aus konfessionellen Konkurrenzen resultierenden und medial ausgetragenen Entladungen wiederum setzen ein gewisses geschichtliches Bedingungsgefüge voraus:

4 Rehberg, ,Öffentlichkeit‘ der Institutionen, 86.

5 Rehberg, ,Öffentlichkeit‘ der Institutionen, 86. 
Zuerst einmal braucht es überhaupt mindestens zwei Konfessionen, die sich sodann - zur theologischen wie rechtlichen Absicherung des je eigenen Anspruchs auf institutionelle Daseinsberechtigung und religiöse Wahrheit zumindest formal auf ein und denselben Referenztext berufen. Gerade dadurch entsteht ja jene Konkurrenz, die die in der betreffenden Leitidee spannungsreich verarbeiteten, eigentlich unvereinbarer Sinnsetzungen und Ordnungsentwürfe wahrnehmbar zutage treten lässt. Und deren Sichtbarwerdung sorgt im Rahmen institutioneller Genese und Selbstbehauptung notwendig für Konflikt.

\section{Historische Ausgangssituation}

So scheint auch die Leitidee der Augsburger Konfessionsverwandtschaft lediglich auf den allerersten Blick rechtlich wie theologisch hinreichend klar: Als Augsburger Konfessionsverwandte sind eben diejenigen, die sich theologisch-dogmatisch und damit kirchlich-institutionell zur Behauptung und Durchsetzung der im Bekenntnistext symbolisch verkörperten Geltungsansprüche affirmativ auf das Augsburger Bekenntnis beziehen, ihm also verwandt sind. Die dadurch ausgezeichnete Ständegruppe ist erstmals im Frankfurter Anstand von 1539 in rechtlich relevanter Weise kollektiv als Augsburger Konfessionsverwandte bezeichnet worden ${ }^{6}$ und genießt unter dieser Formel aufgrund der Festschreibungen von 1555 den Schutz des Reichsrechts. In der juristischen Wahrnehmung der so genannten Augsburger Konfessionsverwandten als sozialer Größe - die sich zu diesem frühen Zeitpunkt schlechterdings nicht einfach als die Gruppe der Lutheraner oder der lutherischen Stände deklarieren lässt ${ }^{7}$ - ist die Sache damit reichsrechtlich zwar vorerst einigermaßen geklärt. Besonders theologisch besteht jedoch sowohl innerhalb der Gruppe wie aus der Außenperspektive von Anfang an Klärungsbedarf.

6 Darauf weist Irene Dingel, Augsburger Religionsfrieden und ,Augsburger Konfessionsverwandtschaft ${ }^{*}$ - konfessionelle Lesarten, in: Heinz Schilling/Heribert Smolinsky (Hg.), Der Augsburger Religionsfrieden 1555. Wissenschaftliches Symposium aus Anlaß des 450. Jahrestages des Friedensschlusses, Augsburg 21. bis 25. September 2005, Gütersloh 2007 (Schriften des Vereins für Reformationsgeschichte 206), 157-76, hier: 157 mit Anm. 3, hin.

7 Vgl. dazu Dingel, Augsburger Religionsfrieden, 158: Die zu dieser Gruppe Gehörigen ,alle als ,lutherisch` oder ,Lutheraner‘ zu bezeichnen und zu konstatieren, daß der Augsburger Religionsfrieden den ,Lutheranern' reichrechtliche Duldung gewährt hätte, geht im Grunde an der unter der Confessio Augustana noch lange bestehenden, ,vorkonfessionellen' theologischen Vielfalt vorbei und projiziert eine sich im Zuge der lutherischen Konfessionsbildung des späten 16. Jahrhunderts festigende Sichtweise zurück in eine konfessionell durchaus noch offene Situation“. 
Von zentraler historischer Bedeutung sind in diesem Zusammenhang die Vorgänge in der Kurpfalz und ihre theologischen, politischen und (reichs-)rechtlichen Folgen: Gerade mit der öffentlichkeitswirksamen Einführung der Reformation melanchthonisch-reformierter Prägung in der Kurpfalz zu Beginn der 1560er Jahre durch Kurfürst Friedrich III. wird der mit dem Augsburger Religionsfrieden gewährleistete reichsrechtliche Schutz des Territoriums anfechtbar ${ }^{8}$ und die Frage der Augsburger Konfessionsverwandtschaft zu einem „tatsächlich reichsrechtliche Konsequenzen heraufbeschwörenden Problem“"9. Schließlich galt der Friedensschluss von 1555 formell - verwiesen sei exemplarisch auf die bündige Formulierung in Artikel 16 - allein ,des Heyligen Reychs Stende[n], der allten Religion anhengig, Geystlich und Weltlich“, sowie eben denjenigen Ständen, „,so der Augspürgischen Confession verwandt" ${ }^{\text {"10 }}$. Entscheidend sind bezüglich des damit benannten, zwei primär religiös divergierende und daher auch rechtssprachlich zu unterscheidende Gruppen umfassenden Geltungsbereichs allerdings zwei weitere Tatsachen: Zum einen sollen nach Artikel 17 dezidiert alle anderen, „so obgemelten bede Religionen nit anhängig, In diesem frieden nit gemeint, sonder gentzlich auß geschlossen sein“"11. Zu dieser exklusiven Formel tritt zum anderen ein dissimulierendes Moment: Der Text des Religionsfriedens lässt offen, welche Fassung der Confessio Augustana in Geltung stehen, ob also die Invariata oder die Variata $^{12}$ die reichsrechtlich maßgebliche Bekenntnisversion

8 S. dazu grundlegend August Kluckhohn, Friedrich der Fromme, Kurfürst von der Pfalz: der Schützer der reformierten Kirche 1559-1576, Nördlingen 1879, 107-85, Wilhelm Holtmann, Die Pfälzische Irenik im Zeitalter der Gegenreformation, Göttingen 1960 [Masch.], 30-92, sowie Volker Press, Die ,Zweite Reformation` in der Kurpfalz, in: Heinz Schilling (Hg.), Die reformierte Konfessionalisierung in Deutschland - Das Problem der „Zweiten Reformation“ in Deutschland, Gütersloh 1986 (Schriften des Vereins für Reformationsgeschichte 195), 104-29.

9 Dingel, Augsburger Religionsfrieden, 162.

10 Der Text des Religionsfriedens wird in modernisierter Wiedergabe zitiert nach: Religiöse Friedenswahrung und Friedensstiftung in Europa (1500-1800): Digitale Quellenedition frühneuzeitlicher Religionsfrieden, hg.v. Irene Dingel, Darmstadt 2013 (Darmstädter Digitale Editionen 1), http://tueditions.ulb.tu-darmstadt.de/e000001/ (10.06.2021).

11 Dingel, Religiöse Friedenswahrung.

12 Zur Entstehungs- und Frühgeschichte der Variata, zu ihrer durchaus gegebenen Geltung unter den Mitgliedern des Schmalkaldischen Bundes und zu ihrem Verhältnis zur Invariata s. Wilhelm Maurer, Confessio Augustana Variata, in: ders., Kirche und Geschichte, Bd. 2: Gesammelte Aufsätze: Beiträge zu Grundsatzfragen und zur Frömmigkeitsgeschichte, hg.v. Ernst-Wilhelm Kohls/ Gerhard Müller, Göttingen 1970, 213-66. Teilweise in kritischer Auseinandersetzung mit Maurer informiert überblicksartig über die (Rezeptions-)Geschichte der Variata Wolf-Dieter Hauschild, Die Geltung der Confessio Augustana im deutschen Protestantismus zwischen 1530 und 1980 (aus lutherischer Sicht), in: ZThK 104 (2007), 172-206, hier: 180 -92. Vgl. zu den verschiedenen Versionen der CA auch Jan Rohls, Die Confessio Augustana in den reformierten Kirchen Deutsch- 
darstellen sollte, ${ }^{13}$ obgleich es durchaus Initiativen zur Festlegung auf die Invariata gab. ${ }^{14}$ Aufgrund dieser Offenheit blieb die Frage letztlich unbeantwortet, wer genau mit der Formel von den Augsburger Konfessionsverwandten gemeint war. Freilich „wussten alle Seiten während der Verhandlungen über den Religionsfrieden sehr genau um ihre Unbestimmtheit“, die aufseiten der reformatorischen Ständegruppe bewusst in Kauf genommen wurde, „barg die nähere Bestimmung des Bekenntnisses doch die Gefahr einer späteren interpretatorischen Einschränkung“ und des grundsätzlichen Verlusts der „Deutungshoheit über die eigene Glaubensgrundlage“ ausgerechnet an die gegnerische Seite. ${ }^{15}$

lands, in: ZThK 104 (2007), 207-45, hier: 207-13. Eine aufschlussreiche Studie zur reichsrechtlichen Stellung der Frage nach der maßgeblichen Bekenntnisfassung liefert Martin Heckel, Reichsrecht und ,Zweite Reformation': Theologisch-juristische Probleme der reformierten Konfessionalisierung, in: Schilling, Die reformierte Konfessionalisierung, 11-43.

13 Martin Heckel, Augsburger Religionsfriede 1555, in: ders., Staat und Kirche nach den Lehren der evangelischen Juristen Deutschlands in der ersten Hälfte des 17. Jahrhunderts, München 1968 (Jus Ecclesiasticum 6), 212, hält dazu fest: „Nach dem Wortlaut blieb unentschieden: Die Frage, welche Fassung der Augsburger Konfession (invariata, variata, ihre Lehrfortbildungen?) maßgeblich war und wer über deren Inhalt, Auslegung, Anhängerschaft (Sektenverbot! Calvinismus!) entschied“. So auch Wolf-Dieter Hauschild, Die Geltung der Confessio Augustana, 177: „Der Religionsfriede machte [...] keinerlei Aussage darüber, welche Fassung der CA (diejenige von 1530 oder diejenige von 1540) für diese Definition [scil. der Augsburger Konfessionsverwandtschaft, C. W.] maßgeblich wäre [...]. So bestimmte eine folgenreiche Äquivokation des Begriffs ,Augsburgische Konfession" die weitere Verfassungsgeschichte“.

14 Zwar sprachen sich 1555 papstkirchliche Reichsstände dafür aus, die Invariata als geltende Fassung festzulegen, doch stießen ihre entsprechenden Bemühungen bei den adressierten Augsburger Konfessionsverwandten auf strikte Ablehnung; s. dazu Axel Gotthard, Der Augsburger Religionsfrieden, Münster 2004 (Reformationsgeschichtliche Studien und Texte 148), 123-25, und Walter Hollweg, Der Augsburger Reichstag von 1566 und seine Bedeutung für die Entstehung der Reformierten Kirche und ihres Bekenntnisses, Neukirchen-Vluyn 1964 (Beiträge zur Geschichte und Lehre der Reformierten Kirche 17), 85-87. Dingel, Augsburger Religionsfrieden, 158f., führt dazu an: „Mit Recht hatten sich die Evangelischen beim Abschluß des Religionsfriedens gegen die von altgläubiger Seite favorisierte Festlegung der Augsburger Konfessionsverwandtschaft auf die erste Fassung der Confessio Augustana, nämlich auf die sogenannte CA invariata von 1530, gewandt. Denn im Zuge der Konsensgespräche mit den Oberdeutschen, die im Jahre 1536 in der Wittenberger Konkordie ihren Höhepunkt erreichten und gleichzeitig ihren Abschluß fanden, hatte Melanchthon das von ihm erstellte Bekenntnis sukzessive an den Stand der Beratungen angepasst“.

15 Armin Kohnle, Theologische Klarheit oder politische Einheit? Die Frage der Geschlossenheit der evangelischen Stände im Jahrzehnt nach dem Augsburger Religionsfrieden, in: Enno Bünz/ Stefan Rhein/Günther Wartenberg (Hg.), Glaube und Macht. Theologie, Politik und Kunst im Jahrhundert der Reformation, Leipzig 2005 (Schriften der Stiftung Luthergedenkstätten in Sachsen-Anhalt 5), 69-86, hier: 72. 
Und hier befindet sich die offene Flanke für die konkurrierenden Geltungsund Deutungsansprüche, die mit den religionspolitischen und konfessionellen Entwicklungen in der Kurpfalz einhergingen: Die Zustimmung Friedrichs III. zum Frankfurter Rezess mit seiner von Melanchthon stammenden vermittelnd-abgeschwächten Abendmahlsformel macht deutlich, dass der Kurfürst bereits 1558 nicht als Verfechter einer Abendmahlslehre gelten konnte, wie sie die Invariata vertrat. ${ }^{16}$ Noch augenfälliger wird Friedrichs Haltung zur Bekenntnisversion von 1530 dann auf dem Naumburger Fürstentag im Jahre 1561: Dort unterschrieb er zwar die Invariata; doch in der beigefügten und ebenfalls die Unterschrift Friedrichs III. tragenden Präfation wurde Melanchthons Überarbeitung jener Bekenntnisschrift von 1540, also die Variata, ausdrücklich ,als authentische Interpretation der CA bestätigt und die Abendmahlslehre Melanchthons so anerkannt“17. „Nun unterschrieben zwar fast alle anwesenden Fürsten bzw. ihre Räte die fragliche Präfation, aber unter dem Einfluß ihrer Theologen zogen sie nach und nach ihre Unterschrift zurück “18, wodurch der Pfälzer Kurfürst abendmahlstheologisch und darüber politisch sowie reichsrechtlich zusehends in die Isolation geriet.

Gleichwohl erhob auch die Kurpfalz den Anspruch, weiterhin zu den Augsburger Konfessionsverwandten zu zählen, zumal Friedrich III. auch und gerade nach seiner öffentlichen Hinwendung zum evangelischen Glauben reformierter Fasson im Jahre 1563 an seinem Bekenntnis eben zur Variata unvermindert festhielt. ${ }^{19}$ Die Reklamation der Augsburger Konfessionsverwandtschaft unbenom-

16 Vgl. dazu Hollweg, Der Augsburger Reichstag von 1566, 95, und Rohls, Die Confessio Augustana, 214.

17 Rohls, Die Confessio Augustana, 213. Vgl. dazu auch Holtmann, Die Pfälzische Irenik, 33-35 und Hollweg, Der Augsburger Reichstag von 1566, 96 f. Über die Vorgänge auf dem Naumburger Fürstentag und die bedeutende Rolle, die der Pfälzische Kurfürst dort für den Verlauf der Ereignisse spielte, informieren ausführlicher Robert Calinich, Der Naumburger Fürstentag 1561. Ein Beitrag zur Geschichte des Luthertums und des Melanchthonismus aus den Quellen des Königlichen Hauptstaatsarchivs zu Dresden, Gotha 1870, (zur in Naumburg unterschriebenen Version der CA und zur Präfation, in der die versammelten Stände erklären, auch an der Variata als authentischer Fortentwicklung der Invariata unbedingt festhalten zu wollen, s. a.a.O., 163-77) und Kluckhohn, Friedrich der Fromme, 83-101.

18 Theodor Kolde, Die Augsburgische Konfession II.: Geschichte des Augsburger Bekenntnisses, in: Die symbolischen Bücher der evangelisch-lutherischen Kirche, deutsch und lateinisch. Mit den sächsischen Visitations-Artikeln, einem Verzeichnis abweichender Lesarten, historischen Einleitungen und ausführlichen Registern, besorgt von Johann Tobias Müller, mit einer neuen historischen Einleitung von Theodor Kolde, Gütersloh ${ }^{10} 1907$, XXI-XXX, hier: XXVIII.

19 Dies belegt u. a. sein Schreiben vom 14.09.1563, in dem er unter Berufung auf den Naumburger Fürstentag und seine dort geleistete Unterschrift seine unverbrüchliche Zugehörigkeit zur CA und die vollkommene Übereinstimmung der von ihm eingeführten Kirchenordnung und des Heidel- 
men der theologischen Entwicklungen und religionspolitischen Maßnahmen im eigenen Territorium war freilich vor dem Hintergrund ihrer reichsrechtlichen Tragweite genauso unabdingbar wie gefährlich. Mit der Veröffentlichung des Heidelberger Katechismus und der Pfälzischen Kirchenordnung wurde die vor dem Hintergrund der konfessionellen Pluralisierung und ihrer Folgen brisante Hinwendung eines der mächtigsten und politisch wichtigsten Territorien des Reiches zum Reformiertentum offenkundig - und damit seine reichsrechtliche Lage prekär. Denn den Schutz des Religionsfriedens von 1555 qua Augsburger Konfessionsverwandtschaft beanspruchte - durch die entsprechenden Voten aus der Kurpfalz zusätzlich alarmiert - die lutherische Ständemehrheit innerhalb des protestantischen Lagers, und zwar unter Verweis auf die Invariata als maßgebliche Bekenntnisfassung.

So wird die institutionelle Selbstkonzeptualisierung als Augsburger Konfessionsverwandte durch Pluralisierung und Konkurrenz der interessengeleiteten Trägerschichten des dahinterliegenden Geltungsanspruchs bei vorangegangener reichsrechtlicher Dissimulation strittig: Wer kann sich in den Reihen der protestantischen Stände nun mit Recht auf den Schutz des Religionsfriedens berufen, wenn doch zwei verschiedene Versionen der Confessio Augustana offen ins Feld geführt werden? Welche Fassung des Bekenntnisses ist die reichsrechtlich maßgebliche und somit die für die Definition der Augsburger Konfessionsverwandtschaft ausschlaggebende? Die Klärung dieser Fragen war für die Aufrechterhaltung des Religionsfriedens genauso virulent wie für den weiteren Weg der reformatorischen Konfessionskirchentümer mit- oder gegeneinander. Ohnehin setzte der Augsburger Religionsfrieden insgesamt „einen nicht enden wollenden Auslegungsstreit in Gang, der sich an seinen verschiedenen, die Koexistenz der beiden ,Religionen` betreffenden Bestimmungen festmachte. Aber auch die Frage, was denn eigentlich unter der ,Augsburger Konfessionsverwandtschaft‘ $\mathrm{zu}$ verstehen sei bzw. wer sich mit Recht der Augsburgischen Konfession verwandt verstehen durfte, blieb noch Jahrzehnte nach 1555 in der Diskussion“20.

berger Katechismus mit jener Bekenntnisschrift herausstellt; s. dazu Heinrich Heppe, Geschichte des deutschen Protestantismus in den Jahren 1555-1581, Bd. 2: Die Geschichte des deutschen Protestantismus von 1563-1574 enthaltend, Marburg 1853, Beilage III, 13f. Heppe bietet auch das dem angeführten Brief Friedrichs III. vorausgehende Sammelschreiben des Pfalzgrafen Wolfgang von Zweibrücken, des Markgrafen Karl von Baden und des Herzogs Christoph von Württemberg vom 04.05. desselben Jahres (a.a.O., Beilage II, 5-11), in dem die genannten drei Fürsten ihrer Sorge wegen der calvinistischen Umtriebe des Kurfürsten Ausdruck verleihen und ihn auffordern, er solle sich „von dem gottlichen wortt, von der rechten wahren Apostolischen kirchen und denn Christlichen Stenden Augspurgischer Confession nicht absondern“ (a.a.O., Beilage II, 10).

20 Dingel, Augsburger Religionsfrieden, 157. 


\section{Theologische Herausforderungen}

Zumindest juristisch erfuhr diese Diskussion mit dem Augsburger Reichstag von 1566 eine gewisse Beruhigung: Der Versuch seitens des von Rom und anfangs auch von bestimmten lutherischen Landesherrn hierin unterstützten Kaisers, die Kurpfalz aus dem Frieden von 1555 auszuschließen und damit Gelegenheit zur „Ausrottung des reformierten Bekenntnisses“ dort zu bekommen, ${ }^{21}$ scheiterte nicht nur am geschickten Verhalten Friedrichs III., ${ }^{22}$ sondern vor allem am Einlenken der lutherischen Fürsten, das letztlich der Initiative Kursachsens zu verdanken war. ${ }^{23}$ Rechtlich begegnete man dem drohenden Verlust der Deutungshoheit über die Frage, wer zu den Augsburger Konfessionsverwandten zu zählen war und wer nicht, ausgerechnet an die papstkirchliche Seite, indem die Juristen im Dienste lutherischer Territorialherren die Confessio Augustana aufspalteten, in einen theologischen und „einen juristischen Bekenntnisbegriff: Sensu theologico gehörten zur CA nur die Lutheraner, sensu politico nahm man auch die Reformierten dazu, obwohl sie nach dem Urteil der reformierten Theologen kaum, nach dem der lutherischen gar nicht zur CA zu zählen waren. So konnten sich die evangelischen Juristen die ungewisse und unerfreuliche Auseinandersetzung mit den Theologen schlichtweg sparen: Der reichsrechtliche Schutz der evangelischen Gesamtpartei blieb ungefährdet durch die inneren orthodoxen SchulenStreitigkeiten um Abendmahl und Prädestination. Desgleichen ließ sich so die theologische Mitsprache und Mitentscheidung der Katholiken in evangelischen Bekenntnisdingen von vornherein abblocken“. ${ }^{24}$

Rechtlich konnte die 1555 aufgerichtete Ordnung also (re-)stabilisiert werden; juristisch wurden die innerhalb der Leitidee der Augsburger Konfessionsverwandtschaft existierenden und sich entladenden Spannungen eingehegt, die

21 Andreas Edel, Der Kaiser und Kurpfalz. Eine Studie zu den Grundelementen politischen Handelns bei Maximilian II. (1564-1576), Göttingen 1997 (Schriftenreihe der historischen Kommission bei der Bayerischen Akademie der Wissenschaften 58), 222. Zur entsprechenden konfessionsübergreifenden Initiative Maximilians II. s. a.a.O., 221-25 und Hollweg, Der Augsburger Reichstag von 1566, 329-49.

22 Martin Heckel, Reichsrecht und ,Zweite Reformation', 20, führt aus, Friedrich III. habe sich dem „heiklen Geschäft [...] mit jener Mischung aus Spitzfindigkeit und bauernschlauer Simplizität unterzogen, wie sie die Situation gebot“.

23 Edel, Der Kaiser und Kurpfalz, 226 - 29; über den Einfluss, den Melanchthons Schwiegersohn Kaspar Peucer auf die kursächsische Linie hatte, und über die daraus resultierende Schwenkung in der Haltung des Kurfürsten August informiert Walter Hollweg, Der Augsburger Reichstag von 1566, 355-68.

24 Martin Heckel, Deutschland im konfessionellen Zeitalter, Göttingen ²2001 (Deutsche Geschichte 5), $80 \mathrm{f}$. 
innerprotestantische Konkurrenz somit zumindest entschärft und die mittels jener Leitidee artikulierten Geltungsansprüche nach außen eingeebnet. Die Reihen der Augsburger Konfessionsverwandten blieben gegenüber den taktisch durchschauten Vorstößen der römischen Partei 1566 weiterhin geschlossen, die evangelische Ständegruppe blieb gegenüber dem Kaiser politisch handlungsfähig. Aus dem „theologischen Begriff der ,Augsburgischen Konfessionsverwandten“ von 1555 war endgültig ein rechtlich-politischer Begriff geworden, der theologische Differenzen nicht ausschloss“25. Doch gerade deshalb blieb die sensu politico stabilisierte Ordnung aus theologischer Perspektive hochgradig fragil, zumal sich die Frage der Augsburger Konfessionsverwandtschaft als Frage nach der reichsrechtlich in Geltung stehenden Fassung der Confessio Augustana mit der Frage nach der rechtgläubigen Abendmahlslehre und folglich mit einem klassischen Kampffeld zwischen Lutheranern und Reformierten verquickte. Das ist freilich ebenfalls kein Zufall, war es doch gerade die Bearbeitung des 10. Artikels durch Melanchthon, die den im Zuge der fortschreitenden konfessionskirchlichen Institutionalisierung theologisch schnell dominanten und daher konfessionell umstrittensten Unterschied zwischen Invariata und Variata ausmachte. Kurz: Der „Streit um die Fassung der CA [...] - invariata oder variata? - als selbstständiges juristisches Problem der Text- und Sinnauslegung des Reichsrechts“ war zwar „wesenlos und irrelevant“ geworden, aber „er blieb [...] als theologisches Problem den Anhängern der CA aufgeben“26.

Damit ist schon angesprochen, dass sich der Sachverhalt seit 1566 gerade für Theologen keineswegs so gestaltete wie für ihre Kollegen aus der Jurisprudenz. Denn der mittlerweile alte Zankapfel, die innerprotestantische Auseinandersetzung um die Abendmahlsfrage, sorgte in seiner Verbindung mit der bereits erheblich fortgeschrittenen Institutionalisierung der reformatorischen Konfessionskirchentümer einerseits, anderseits mit der als problematisch empfundenen Offenheit des Religionsfriedens bezüglich der Definition der Augsburger Konfessionsverwandtschaft nach wie vor für Klärungsbedarf. Dieser war auch 1566 trotz der Anerkennung der Konfessionsverwandtschaft Friedrichs III. sensu politico keineswegs ausgeräumt worden. Nun hatte man dem Kaiser auf dem Reichstag zwar eine baldige Beilegung des theologischen Konflikts, der angesichts der schwelenden Versionsfrage eben auch eine reichsrechtlich-politische Dimension

25 Armin Kohnle, Theologische Klarheit oder politische Einheit?, in: Bünz/Rhein/Wartenberg, Glaube und Macht, 84.

26 Martin Heckel, Die reichsrechtliche Bedeutung der Bekenntnisse, in: Martin Brecht/Reinhard Schwarz (Hg.), Bekenntnis und Einheit der Kirche. Studien zum Konkordienbuch im Auftrag der Sektion Kirchengeschichte der Wissenschaftlichen Gesellschaft für Theologie, Stuttgart 1980, 57-88, hier: 77. 
hatte, versprochen, doch eine endgültige Lösung des Streits blieb weiterhin aus, ohne an Dringlichkeit zu verlieren. ${ }^{27}$

Schließlich wurde die Lage durch die in der Veröffentlichung des Konkordienbuches 1580 gipfelnden Einigungsbemühungen auf lutherischer Seite ${ }^{28}$ nachhaltig verschärft. Sie zielten insgesamt darauf ab, „die im Protestantismus unter den Schülern Luthers und Melanchthons aufgebrochene und kontrovers diskutierte lehrmäßige Vielfalt auf der Grundlage der Lutherschen Theologie zu bekenntnismäßiger Eindeutigkeit und Einhelligkeit zurückzuführen“29. Die Konkordienformel in ihrem Selbstverständnis als „Gründliche, [Allgemeine], lautere, richtige und endliche Wiederholung und Erklärung etlicher Artikel Augsburgi-

27 S. dazu Andreas Edel, Der Kaiser und Kurpfalz, 246: „Ein für die kaiserliche Religionspolitik wichtiges Ergebnis des Reichstages von 1566 war die Zusage der Evangelischen, sich mit Friedrich III. in absehbarer Zeit auf einem innerevangelischen Konvent über die theologischen Streitpunkte zu vergleichen“. Im September 1566 kam es daher zu einer Versammlung der Räte evangelischer Reichsstände in Erfurt, „um sich über die Modalitäten des geplanten Konvents abzustimmen“ (a.a.O., 248). Doch schon in Erfurt brachen Streitigkeiten um die Frage aus, ob die Räte der Kurpfalz wegen des Bekenntnisses ihres Landesherrn überhaupt an der Versammlung teilnehmen durften oder nicht; deshalb und wegen der mangelhaften Beschickung der Erfurter Konferenz einigte man sich auf eine Vertagung der Räteversammlung. Allein, die geplante neuerliche Zusammenkunft kam nicht mehr zustande (a.a.O., 247-49). Damit waren die 1566 dem Kaiser in Aussicht gestellten innerevangelischen Einigungsbemühungen gescheitert, und zwar an genau dem problembehafteten Thema, das schon auf dem Reichstag jenes Jahres den Gang der Verhandlungen bestimmt hatte und dort nur mit viel Mühe zu einer glimpflichen, aber eben nicht endgültigen Lösung gelangte, nämlich an der Bekenntnishaltung der Kurpfalz und ihrer Legitimität angesichts der Bestimmungen von 1555. Vgl. zur Rätekonferenz in Erfurt, zu den dahinterstehenden Motiven der die Versammlung beschickenden Stände und zum Scheitern der Einigungsbemühungen auch Walter Hollweg, Der Augsburger Reichstag von 1566, 391-97.

28 Eine luzide Einbettung der lutherischen Einigungsbemühungen in den auch nach 1566 nicht nachlassenden Konflikt um den Bekenntnisstand der Kurpfalz und in die damit verbundenen Entwicklungen auf politischer, theologischer und reichsrechtlicher Ebene unternimmt Hans Leube, Kalvinismus und Luthertum im Zeitalter der Orthodoxie, Bd. 1: Der Kampf um die Herrschaft im protestantischen Deutschland, Leipzig 1928, 16-32. Zu diesen Zusammenhängen bleiben grundlegend Irene Dingel, Concordia controversa. Die öffentlichen Diskussionen um das lutherische Konkordienwerk am Ende des 16. Jahrhunderts, Gütersloh 1996 (Quellen und Forschungen zur Reformationsgeschichte 63), und Wolf-Dieter Hauschild, Corpus Doctrinae und Bekenntnisschriften. Zur Vorgeschichte des Konkordienbuches, in: Brecht/Schwarz, Bekenntnis und Einheit der Kirche, 235-52. Zum Einfluss des Konkordienbuches auf die primär theologische lutherische Traditionsbildung s. Friederike Nüssel, Das Konkordienbuch und die Genese einer lutherischen Tradition, in: Peter Gemeinhardt/Bernd Oberdorfer (Hg.), Gebundene Freiheit? Bekenntnisbildung und theologische Lehre im Luthertum, Gütersloh 2008 (Die Lutherische Kirche Geschichte und Gestalten 25), 62-83.

29 Dingel, Augsburger Religionsfrieden, 163. 
scher Confession“"30 erklärt mehrfach ausdrücklich die Invariata zur allein maßgeblichen Fassung der Confessio Augustana ${ }^{31}$ und fordert so indirekt von allen, die sich legitimerweise als Konfessionsverwandte bezeichnen und sich somit unter den Schutz des Religionsfriedens stellen wollten, die uneingeschränkte Anerkennung jener Bekenntnisversion. Die damit einhergehende kollektive Festlegung weiter Teile der Reichsstände auf die Invariata wirkte naturgemäß zurück auf die Debatte um die Reichweite der Augsburger Konfessionsverwandtschaft und folglich auf den Geltungsbereich der Friedensbestimmungen von 1555.

Mit der Unterzeichnung der Konkordienformel und der Annahme des Konkordienbuches wurde eine bestimmte Lesart des Religionsfriedens durch ein bestimmtes exklusives Verständnis der Augsburger Konfessionsverwandtschaft öffentlichkeitswirksam, die die Konkurrenz um die Deutungshoheit jener Leitidee zugunsten einer konfessionellen Partei aufzuheben drohte. Die aufgezeigte Dissimulation des Vertragstextes wurde so ex post durch eine spezifische Engführung inhaltlich-argumentativ behoben und die einst „bewußt offene Bezeichnung der Evangelischen als Augsburger Konfessionsverwandte auf die Gruppe der Anhänger der Confessio Augustana invariata und damit auf die ,Lutheraner` eingegrenzt bzw. zurückgenommen“32. Die bereits 1566 sensu politico stabilisierte Ordnung sollte also in und mit einem weiteren Schritt konfessioneller Institutionalisierung und Profilierung nachträglich auch sensu theologico stabilisiert werden, und zwar durch einseitige Initiative, inhaltliche Klarstellung, strukturelle Reduktion und exklusive Selbstzuschreibung. Entsprechend sollte innerhalb der Leitidee der Augsburger Konfessionsverwandtschaft einem konfessionell spezifischen Ordnungsentwurf zur Durchsetzung verholfen werden, um der herrschenden störenden Konkurrenz um jene reichsrechtlich wie theologisch bedeutsame Leitidee im Rahmen institutioneller Selbstkonzeptualisierung ein Ende zu setzen und so die betreffende Leitidee selbst als singulär, homogen und eindeutig erscheinen zu lassen.

30 Schon das Titelblatt enthält diese Formulierung; s. dazu: Die Bekenntnisschriften der evangelisch-lutherischen Kirche, herausgegeben im Gedenkjahr der Augsburgischen Konfession 1930, Göttingen ${ }^{2} 1955$ [künftig: BSLK], 735.

31 ,[S]o bekennen wir uns auch zu derselben ersten ungeänderten [...] Augsburgischen Confession, nicht derwegen, daß sie von unsern Theologis gestellt, sondern weil sie aus Gottes Wort genommen und darinnen fest und wohl gegründet ist, allermaßen wie sie Anno etc. 30. in Schriften vorfasset und dem Kaiser Carol V. [...] als ein allgemein Bekenntnus [...] zu Augsburg übergeben, als dieser Zeit unserm Symbolo“ (BSLK, 835; s. beispielsweise auch a.a.O., 740 f., 745, 750 f., 761, 768, 830). Vgl. dazu prägnant Reinhold Seeberg, Lehrbuch der Dogmengeschichte, Bd. 4/2, Die Fortbildung der reformatorischen Lehre und die gegenreformatorische Lehre, Darmstadt ${ }^{4} 1954$, 536, und Hans Leube, Kalvinismus und Luthertum, 18.

32 Dingel, Augsburger Religionsfrieden, 163. 


\section{Konfessionelle Klärungsbestrebungen}

Die damit nun einhergehende, auch und gerade wegen der reichsrechtlichen Tragweite existentielle Bedrohung für die Kurpfalz und andere reformierte Reichsstände, die die durch das Konkordienwerk forcierte lehrmäßige Festlegung auf die Invariata aus konfessionspolitischen und theologischen Gründen ablehnten, war manifest. Der für das eigene Überleben so wichtige Schutz durch die Bestimmungen von 1555 war durch die konfessionell einseitige Behebung der dissimulierenden Formulierungen des Vertragstextes durch gleichermaßen exklusive wie Allgemeingültigkeit beanspruchende Festlegung auf eine bestimmte Version des Augsburger Bekenntnisses massiv gefährdet. Das sich so verschärfende Bedrohungsszenario für das Reformiertentum in all seinen Schattierungen im Reich forderte mit Blick auf die Qualität der möglichen juristischen und politischen Konsequenzen Maßnahmen von reformierter Seite. So war der entscheidende Impuls gegeben, das Thema der Augsburger Konfessionsverwandtschaft theologisch-publizistisch $\mathrm{zu}$ verhandeln, und in der durch die Konkordienformel mit ihrer Festlegung auf die Invariata reichsrechtlich und religionspolitisch schwer unter Druck geratenen Kurpfalz ${ }^{33}$ nahm man sich der Herausforderung initiativ an.

Entsprechend ist die Christliche Erinnerung Vom CONCORDIBVCH des Zacharias Ursinus von 1581 nicht zuletzt dem Streben geschuldet, reformierterseits theologisch wie historisch die eigene Konfessionsverwandtschaft und darüber die Unanfechtbarkeit des Schutzes des Religionsfriedens für die eigene Partei zu er-

33 Zusätzlich erschwert wurde die Situation des stark melanchthonisch geprägten Pfälzer Reformiertentums noch durch die konfessionelle Haltung des Kurfürsten Ludwig VI., des Sohnes und seit 1576 Nachfolgers Friedrichs III., der 1579 die Konkordienformel unterzeichnete; zu Ludwig VI. und sein Verhältnis zum Konkordienwerk vgl. Irene Dingel, Concordia controversa, 103f. und 109f. Nach Ludwigs Verwerfung der reformierten Kirchenordnung seines Vorgängers und der damit einhergehenden lutherischen Reaktion in der Kurpfalz flüchteten sich die vormals unter Friedrich III. zu Einfluss gelangten reformierten Gelehrten zum Bruder des Kurfürsten, Johann Kasimir, in das neubegründete Herzogtum Pfalz-Lautern. Erst nach dem Tode Ludwigs VI. im Jahre 1583 und dem Regierungsantritt des überzeugt reformierten Johann Kasimir, der als Vormund des späteren Kurfürsten Friedrich IV. die Herrschaft innehatte und als entschiedener Gegner des lutherischen Konkordienwerkes gelten muss, entspannte sich die Lage für die Anhänger des durch Friedrich III. zur Durchsetzung gelangten Reformiertentums in der Kurpfalz wieder. Vgl. zu Johann Kasimirs Ablehnung des Konkordienwerkes und seinen dagegen eingeleiteten Maßnahmen Hans Leube, Kalvinismus und Luthertum, 22-26, und Irene Dingel, Concordia controversa, 104-29. 
weisen. ${ }^{34}$ Ursin erklärt zum Zweck seines Werkes, „daß wir hiemit nichts anders suchen noch meinen/ denn die Ehre Christi/ das Heil gemeiner Kirchen vnd gemeines Vaterlands/ vnd aller darinnen Augspurgischer Confession zugethanen/ Hohes vnnd nidern Stands/ Ehr/ glimpff/ zeitliche vnnd ewige wolfart“"35. Zu den genannten Augsburger Konfessionsverwandten sind freilich auch die Reformierten zu zählen, zumal die von ihnen vertretene Lehre mit dem Augsburger Bekenntnis völlig übereinstimme, „so nur dieselbe recht vnd also verstanden wird/ daß sie mit der Schrifft vnd ihr selbst nicht streite“36. Die Frage nach der einzig legitimen Fassung der Confessio Augustana ist somit aufs Tapet gebracht, und Ursins Antwort darauf fällt eindeutig aus: Die Änderungen an der Augsburger Konfession, die Melanchthon in der Variata vorgenommen habe, seien „geschehen bey leben/ mit wissen vnd verwilligung Lutheri. Ist derwegen ein grosse frechheit der jenigen/ die vber den frommen ehrlichen Mann Philippum Melanchthon dürffen schreien/ er hab dieselben heimlich vnd betrüglich beigeschoben“, zumal die mit Wissen Luthers erfolgten Änderungen einst die offizielle Bestätigung „von allen Augspurgischer Confession verwandten“ erhalten hätten. ${ }^{37}$ Demnach sei 1540 nichts am Bekenntnis „wider aller seiner mitverwandten willen vnnd gutheissung“38 geändert worden.

Die breitestmögliche Zustimmung zur Variata unter den Augsburger Konfessionsverwandten sei den entstehungsbedingten Eigenheiten der Invariata zu danken: Diese sei 1530 ,geschrieben und vbergeben worden/ inn grosser furcht damals fürstehender gefahr/ in welche die Protestirenden/ bey Keiser vnd Fürsten gesetzt wurden/ durch der Papisten häßliche verleumdungen/ blutdürstigen rath

34 Zacharias Ursinus, Christliche Erinnerung Vom ConcoRdibvch So newlich durch etliche Theologen gestelt/ Vnd im Namen etlicher Augspurgischer Confession verwandten Stände publicirt/ Der Theologen und Kirchendiener in der Fürstlichen Pfaltz bey Rhein. Auß dem Latein verteutscht/ Vnd an etlichen orten weiter außgeführt, Neustadt a.d. Hardt 1581. Die vorangegangene lateinische Version erschien unter dem Titel: DE Libro ConcoRdiAe quem vocant, A quibusdam Theologis, nomine quorundam Ordinum Augustanae Confessionis, edito, ADMonitio Christiana: Scripta a Theologis et Ministris Ecclesiarum in ditione Illustrißimi Principis IoHANNIS CAsimiri Palatini ad Rhenum Bauariae Ducis, etc., Neustadt a.d. Hardt 1581. Zur Verfasserschaft Ursins s. Wilhelm Holtmann, Die Pfälzische Irenik, 149, und Irene Dingel, Concordia controversa, 141; zur genauen Kontextualisierung dieser „,wohl gründlichsten und fundiertesten Gegenschrift zur Konkordienformel“ vgl. Wilhelm Holtmann, Die Pfälzische Irenik, 127-50 (das Zitat findet sich a.a.0., 149).

35 Ursinus, Christliche Erinnerung, 15.

36 Ursinus, Christliche Erinnerung, 191. Vgl. dazu auch a.a.O., 23 und $239 \mathrm{f}$.

37 Ursinus, Christliche Erinnerung, 269f. Bei der Aufzählung der Gelegenheiten, zu denen die CA Variata als statthafte Verbesserung der Invariata allgemein gebilligt worden sei, nennt Ursin selbstverständlich auch den Frankfurter Rezess und den Naumburger Fürstentag (a.a.O., 270f.). 38 Ursinus, Christliche Erinnerung, 270. 
vnd hetzung“, weshalb man sich ,in der Confessionformul beflissen/ den grewel vnd Abgötterey deß Papstums/ in denen Articuln/ dauon man zur selben zeit etwas zuschreiben für gut vnd noth angesehen/ auffs kürtzest vnnd leisest/ so möglich war/ anzurüren. Daher ist vieler Artickel/ die verhasset waren/ kein meldung geschehen/ vnd allein die ding widersprochen/ darob Keis. Maiestet nicht so hart hielt“"39. Insofern hält Ursin eine adäquate, also gleichsam historischkritische Interpretation der Lehraussagen der Invariata für unerlässlich, lassen sich in ihr doch eben wegen ihres spezifischen Genesekontextes bestimmte Lehraussagen finden, mit denen aus guten theologischen Gründen „nicht alle reformirte/ rechtglaubige Kirchen zufrieden“ seien. ${ }^{40}$ Betroffen davon ist in erster Linie der Abendmahlsartikel in seiner Formulierung von 1530, ${ }^{41}$ sodass selbst lutherische Theologen zugäben, „daß durch die enderungen/ die Confession nicht verbösert/ sonder verbessert sey. Wie stimmen sie denn mit einander/ vnd mit sich selbst/ weil sie das für ein verfelschung schelten/ das sie anderßwo als ein billiche vnd nützliche verbesserung loben?“42

Angesichts der geschichtlich begründbaren Defizite der Invariata im Vergleich zur unter den Augsburger Konfessionsverwandten vormals konsensfähigen Überarbeitung von 1540 stellt sich Ursin die Frage, warum ausgerechnet jene Fassung des Bekenntnisses Eingang in das Konkordienbuch gefunden hat und nicht etwa die von Melanchthon verbesserte Version. Der Grund für diesen Fehlgriff steht ihm allerdings klar vor Augen: Die Invariata sei aus keiner anderen Ursache ausgewählt worden als der, dass sich in der Variata lehrmäßig rein gar nichts finden lasse, „das wider uns sey/ vnnd vermeinen [scil. die Schöpfer und Verfechter des Konkordienbuches, C. W.]/ sie wollen aus dem ersten etwas herfür kratzen. Damit aber bekennen sie/ daß die erfolgten Exemplar auff vnser seiten stehen. Diß nemen wir von jnen für bekannt $\mathrm{an}^{\text {“43 }}$. Vor diesem Hintergrund ist es nicht nur unrechtmäßig, sondern auch Ausdruck unchristlicher Böswilligkeit und Engherzigkeit, die Reformierten „zuverdammen/ vnd aus der Christlichen Kirchen

39 Ursinus, Christliche Erinnerung, $228 \mathrm{f}$.

40 Ursinus, Christliche Erinnerung, 218; vgl. dazu auch a.a.O., 234f. „Reformirte Kirchen“ ist dabei Ursins Integrationsbezeichnung zur Benennung der Gesamtheit der lutherischen und reformierten Kirchentümer (s. dazu exemplarisch auch a.a.O., 11, 215, 221, 232, 235, 307, 421, 617, 620, 629, 633, 681, 726, 730, 741, 749). Daneben kann er auch von „Euangelischen Kirchen“ oder schlicht von „Euangelischen“ sprechen, wenn es ihm darum geht, der Geschlossenheit von Reformierten und Lutheranern terminologisch Ausdruck zu verleihen (vgl. dazu beispielsweise a.a.O., 232, 415, 422, 525, 619, 648, 731, 746, 748, 753, 763, 804f.).

41 Ursinus, Christliche Erinnerung, 241. Vgl. dazu auch a.a.O., 648.

42 Ursinus, Christliche Erinnerung, 269.

43 Ursinus, Christliche Erinnerung, $266 \mathrm{f}$. 
und Confessionsverwandschafft/ als Ketzer außzuschließen“44. Dagegen gelte es im protestantischen Lager, „die Christliche Brüderschafft vnd einigkeit der Kirchen“ zur wirksamen Abwehr papstkirchlicher Nachstellungen zu behaupten ${ }^{45}$ und in dieser Stoßrichtung genauso offen wie selbstbewusst zu erklären, dass die Lutheraner „mit samt vns/ Aug. Confession verwandt seind/ [...] wegen der wahren wesentlichen gemeinschafft deß leibs Christi/ welche sie mit uns/ vermög der Confession/ bekennen“446.

Den skizzierten argumentativen Bahnen Ursins folgt das 1614 erschienene Irenicum seines Schülers David Pareus. ${ }^{47}$ Auch Pareus widmet sein Werk neben Überlegungen zur Aussöhnung zwischen Reformierten und Lutheranern dem Nachweis der Augsburger Konfessionsverwandtschaft der erstgenannten Partei. In diesem Kontext hält er grundsätzlich fest, 1566 seien illi, qui Calviniani vocantur, ab Imperatoria Maiestate, \& a Statibus Protestantibus pro sociis Confessionis agniti, \& pace Religionis comprehensi ${ }^{48}$, nachdem auf dem betreffenden Augsburger Reichstag bereits Friedrich III. öffentlich als socius Augustanae Confessionis anerkannt worden sei. ${ }^{49}$ Dass anno 1566. in comitiis Augustanis Protestantes utriusque partis inter se convenisse, \& Calvinistas, quos vocant, pro sociis Confessionis a Caesarea Maiestate \& Ordinibus reliquis agnitos, paceque religionis comprehensos esse $e^{50}$, ist dem Heidelberger Theologen zentrale Voraussetzung für

44 Ursinus, Christliche Erinnerung, 423.

45 Ursinus, Christliche Erinnerung, 627.

46 Ursinus, Christliche Erinnerung, 747.

47 David Pareus, Irenicum sive DE Unione et Synodo Evangelicorum Concilianda LibeR votivus Paci Ecclesiae \& desiderijs pacificorum dicatus [...], Heidelberg 1614. Im Jahr darauf erfuhr das Irenicum eine deutsche Übersetzung: IRENICUM Oder Friedemacher/ Wie die Evangelischen Christlich zuvereinigen/ vnd zu einem Synodo, oder allgemeinen Versamblung gelangen mögen/ Dem lieben Kirchen Frieden zu Förderung/ vnd allen Friedliebenden zu Gefallen geschrieben Durch Herrn David PAREUM der heyligen Schrifft Doctor. Vnd nun auß dem Latein ins Teutsch gebracht/ Durch Herrn GwINANDvm Zonsivm Pfarrherrn vnd Inspectorn zu Bretta. Sampt einer Vorrede/ vnd newen Erinnerungen an den Christlichen Leser, Frankfurt a.M. 1615. Einen inhaltlichen Überblick und eine theologiegeschichtliche Einordnung dieses prominenten Werkes bieten Wilhelm Holtmann, Die Pfälzische Irenik, 238-60 und Gustav Adolf Benrath, Irenik und Zweite Reformation, in: Schilling, Die reformierte Konfessionalisierung, 349-58. Bedenkenswert sind daneben die kritischen Beobachtungen in Hans Leube, Kalvinismus und Luthertum, 59-73. Dieser Linie folgt analytisch Christian Volkmar Witt, Keine Irenik ohne Polemik. Konfessionelle Wahrnehmungsformationen am Beispiel des David Pareus, in: ders./Malte van Spankeren (Hg.), Confessio im Barock. Religiöse Wahrnehmungsformationen im 17. Jahrhundert, Leipzig 2015, $17-53$.

48 Pareus, Irenicum, 297.

49 Pareus, Irenicum, 293.

50 Pareus, Irenicum, 304. 
die dauerhafte reichsrechtliche Absicherung der Kurpfalz und darüber hinaus für den von Reformierten und Lutheranern gemeinsam zu führenden Abwehrkampf gegen den altbösen Feind zu Rom und seine Handlanger. Denn wie für die Lutheraner gilt auch für die Reformierten: Non damnamus, neque rejicimus confessionem Augustanam ${ }^{51}$, solange diese nur secundum Scripturam divinarum mentem verstanden werde; ${ }^{52}$ von den Reformierten das Gegenteil zu behaupten stelle jedenfalls eine ridiculam magis an malitiosam criminationem dar. ${ }^{53}$

Der Anspruch auf Anerkennung der eigenen Augsburger Konfessionsverwandtschaft wird bald auch jenseits der Grenzen der Kurpfalz und für die kommenden Jahrzehnte laut. In Bremen erklärt Christoph Pezel in seinem Wahrhaffte[n] Bericht von 1591 unter Verweis auf die Ereignisse von 1566 die Reformierten genauso zu Augsburger Konfessionsverwandten ${ }^{54}$ wie wenige Jahre später von Herborn aus Wilhelm Zepper in seinem Christlich Bedencken/ Vorschlag vnd Raht ${ }^{55}$. Selbstbewusst tragen Christian Beckmanns 1621 publizierte Ausführliche Behauptung ${ }^{56}$ und

51 Pareus, Irenicum, 273.

52 Pareus, Irenicum, 292.

53 Pareus, Irenicum, 275.

54 Christoph Pezel, Wahrhaffter Bericht Von den vorbesserten Exemplarn Augsp. Confession: Vnd Warümb es eigentlich zuthun sey inn dem Streit vom Heiligen Nachtmal. Vnnd daß Philippo Melanchthoni vngütlich zugelegt werde/ als solte er nach D. Luthers Tode erst eine newe Lehr vom Abentmal eingefüret haben. Zu Gründlicher Widerlegung Der genanthen letzten Bekendtnus vnd Testaments/ D. Nicolai Selnecceri. Vnd zu Christlicher Warnung guthertziger Leuth/ Damit sie im Grund erkennen mögen/ daß solcher D. Selneckers widerholten letzten Bekentnus gar nicht zugetrawen sey/vnd daß die jenigen sich gentzlich werden betrogen finden/ die von dem Testament Jesu Christi/ vnd desselben rechtem/ wahrhafftem/ vnd tröstlichem Verstandt/ auff das nichtige vnnd betrigliche Selneckerische Testament sich abfüren lassen/ alß welches anders nicht ist/ dann eine Vorwirrung der heilsamen Lehr vom Heiligen Abentmal/ vnnd ein solches Gemenge/ das durchaus zweiffelhafftig vnd vngewiß ist/ darinnen Jha zugleich Nein/ vnd Nein zugleich Jha heissen mus, Bremen 1591, 8f.

55 Wilhelm Zepper, Christlich Bedencken/ Vorschlag vnd Raht/ Durch waserley mittel vnd wege dem hochbetrübten zustand der Kirchen Gottes/ wegen der vnchristlichen/ ergerlichen spaltungen/ lästerns/ verketzerns vnd verdammens zwischen den Euangelischen Kirchen und Lehrern: auch derenthalben besorglichen/ ja vngezweifelten straffen Gottes/ vnd vndergang der Euangelischen Stände/ vermittelst götlicher gnaden/ bey zeiten vorzukomen vnd abzuhelffen seyn möge. Mit der alten Christlichen Kirchen/ Keyser vnd Lehrer exempeln/ vnd darneben gehaltenen newen gemeinen Constitutionen im heiligen Römischen Reich/ zusamt besondren Abschieden/ Handlungen vnd Edicten der Protestirenden Ständen befestiget vnd bewehret, Herborn 1594, 105-11.

56 Christian Beckmann, Ausführliche Behauptung der verbesserten Augspurgischen Confession vnd etlicher dazu gehörigen materien/ Das ist: Gründliche Beweise/ daß die verbesserte Augspurg. Confession niemals bey lebzeiten Herrn D. Martini Lutheri/ auch nit etliche jahre nach seinem sehligen abscheide den Euangelischen Protestierenden Ständen sey verdächtig gewesen: sondern das sie viel mehr so wol von D. Mart. Luth. selbst/ als auch allen Protestierenden Ständen vnd dero 
Heinrich Altings EXEgEsIS Logica \& Theologica AugustanAE Confessionis von $1647^{57}$ den Anspruch gleich im Titel. Mit Nachdruck stellt Alting, vor der politischmilitärischen Katastrophe Friedrichs V. dessen Lehrer und Professor in Heidelberg, später Flüchtling in den Niederlanden, dann auch heraus, Reformatas per Germaniam Ecclesias pro Augustanae Confeßionis sociis agnoscendas \& habendas es$s e^{58}$. Nicht minder offen - nämlich ebenfalls bereits im Titel - trägt schließlich Johann Crocius im selben Jahr wie Alting die Selbstwahrnehmung des Reformiertentums vor: In seinem in Kassel gedruckten Commentarius De AugustanaE Confessionis Societate erklärt er begründend, Friedrich III. habe die Confessio Augustana 1561 eigenhändig unterschrieben, woraufhin ihn der Kaiser persönlich damals als confessionis Augustanae socium anerkannt habe. ${ }^{59}$ Und wie seinerzeit

Theologis/ keinen ausgenommen zu derselben zeit sey beliebet vnd gebilliget worden: Dann auch/ Das Johannes Calvinus beydes von D. Mart. Luth. vnd von allen Protestirenden Theologis/ wie auch von Fürsten vnd Ständen für ein gliedmas der Augsp. Confession sey gehalten: die von ihme also genanten Calvinisten auch im Religionsfried seind begriffen/ vnd von samtlichen Ständen für glaubensgenossen erkant worden: Fürnemlich aus theils Lutherischen/ theils Bäpstlichen Scribenten trewlich in zweyen Schreiben zusammen gezogen, ohne Ortsangabe 1621.

57 Heinrich Alting, Exegesis Logica \& Theologica Augustanae Confessionis: cum Appendice Problematica; Num Ecclesiae Reformatae in Germania pro Sociis Augustanae Confeßionis agnoscendae \& habendae sint? Accessit Syllabus Controversiarum Quae Reformatis hodie intercedunt cum Lutheranis, Amsterdam 1647.

58 Alting, EXegesis, 116. S. dazu auch den Syllogismus a.a.O., 117: Quae Ecclesiae de omnibus articulis doctrinalibus, uno, eoque non toto, nec fundamentali excepto, idem sentiunt cum Augustana Confessione: \& Consensum suum publice testificati sunt \& approbarunt; eae pro sociis Augustanae Confessionis merito agnoscendae \& habendae sunt. Atqui Ecclesiae Reformatae per Germaniam, de omnibus articulis doctrinalibus, uno, eoque non toto, nec fundamentali excepto, idem sentiunt cum Augustana Confessione \& consensum suum publice testificati sunt \& approbarunt. Ergo Ecclasiae Reformatae per Germaniam pro Sociis Augustanae Confessionis merito agnoscendae \& habendae sunt.

59 Johann Crocius, Protestantium paci sacer Commentarius De Augustanae Confessionis SoCIETATE, Quo demonstratur, Reformatos Ordines \& coetus NEC EA VNQVAM EXClvsos, CAVSA RITE COGNITA, CONSENTIENTIBvs Protestantium reliquorum suffragiis, Nec leges, opiniones \& ceremonias a Regiomontano ministerio praescriptas recipere sub exclusionis periculo teneri, Solutis complurium theologorum politicorumque argumentis, Ex ImPERATORUM, REgum, Principum, aliorum dictis, factis, Itemque Comitiorum Imperii, principalium Conventuum, Synodorum, Colloquiorum Actis, Protocolis, aliis historiae secularis \& ecclesiasticae monumentis, In Serenissimi Electoris Brandeburgici, Dn. Johannis Sigismundi, nunc coelitis, causa primum consignatus, dein varie auctus \& bono tandem publico in lucem editus, Kassel 1647, 62f.: Fridericus Palatinus Septemvir anno sexagesimo primo cum caeteris Electoribus \& Principibus confessioni propria manu subscripsisset Naumburgi, eamque Ferdinando Imperatori obtulisset, hic eum non excludit, ob doctrinae nostrae professionem, Electoratu, quem ipso regnante adiverat, non movet, sed confessionis Augustanae socium agnoscit. 
der Pfälzer Kurfürst hätten sowohl seine Nachfolger als auch andere reformierte Fürsten sie als ihr Bekenntnis angenommen. ${ }^{60}$

Die hier nur in aller gebotenen Kürze angeführten Voten reformierter Provenienz, deren Liste sich mit wenig Aufwand noch erheblich erweitern ließe, illustrieren gleichsam den steigenden Druck, aber eben auch das wachsende Selbstbewusstsein des Reformiertentums im Reich seit der Festlegung weiter Teile des Luthertums auf die Invariata in und mit Konkordienformel und Konkordienbuch. Bis dahin hatte man sich mit der Berufung auf die Variata beholfen und zugleich aufseiten der lutherischen Ständemehrheit auf die Einsicht vertraut, dass gegenüber der papstkirchlichen Agitation die Geschlossenheit der protestantischen Reihen überlebensnotwendig ist. Besonders die Ereignisse von 1566 gaben dieser Doppelstrategie recht. Doch ab den späten 1570er Jahren verschärfte sich mit den genannten lutherischen Einigungsbemühungen die Situation in einem solchen Maße, dass sich nun die Notwendigkeit verbindlicher Klärung zur nachhaltigen Stabilisierung der ohnehin fragilen reichsrechtlichen Situation ergab. In diesem Zusammenhang traten in den folgenden Dekaden immer wieder reformierte Theologen zwecks Nachweis der eigenen Augsburger Konfessionsverwandtschaft und darüber der Legitimität des - anfechtbaren und wiederholt angefochtenen - Schutzes des Reformiertentums durch den Religionsfrieden in die Schranken.

Während allerdings reformierte Theologen in historisch-rechtlichen und dogmatischen Argumentationsgängen beständig die Augsburger Konfessionsverwandtschaft ihrer Konfession bzw. der ihr zugehörigen Kirchentümer im Reich behaupteten, um der Gefahr des Ausschlusses aus dem Friedensschluss von 1555 zu entgehen, sperrte sich das fest auf dem Boden der Konkordienformel mit ihrem klaren Bekenntnis zur Invariata stehende Luthertum mit aller Konsequenz und Vehemenz gegen jene reformierten Bemühungen. An eine Anerkennung der sogenannten Calvinisten als Konfessionsverwandte oder socii confessionis war für Theologen wie Johann Georg Sigwart, Leonhard Hutter, Matthias Hoe von Hoenegg oder Abraham Calov schlicht nicht zu denken. In ihrer diesbezüglichen Argumentation schöpften sie, wie die Gegenseite, aus historisch-rechtlichen und theologischen Begründungen und gelangten dabei zum diametral entgegengesetzten Ergebnis: Die von den Reformierten eingeforderte Akzeptanz ihrer Konfessionsverwandtschaft sei letztlich, wie die Sachlage unzweifelhaft beweise, nichts weiter als blanke Anmaßung. ${ }^{61}$

60 Crocius, Protestantium, 534.

$61 \mathrm{Zu}$ den entsprechenden Schriften der genannten Vertreter des Konkordienluthertums s. Christian Volkmar Witt, Protestanten. Das Werden eines Integrationsbegriffs in der Frühen Neuzeit, Tübingen 2011 (Beiträge zur historischen Theologie 163), 91-120. 


\section{Reichsrechtliche Integration}

Als die Werke Altings und Crocius' veröffentlicht werden, sind die Verhandlungen um einen die blutigen Waffengänge der europäischen Mächte beilegenden Friedensschluss in vollem Gange und nähern sich allmählich ihrem Ende. Dabei boten die Verhandlungen, die um eine Beendigung des Dreißigjährigen Krieges geführt wurden, auch die Gelegenheit, jene Offenheit bezüglich der Augsburger Konfessionsverwandtschaft, die den Religionsfrieden von 1555 kennzeichnete, mittels reichsrechtlicher Klarstellung zu beheben - und diese Gelegenheit wurde genutzt.

Im Verlauf der Verhandlungen zum Westfälischen Frieden gelingt es den reformierten Reichsständen mit Unterstützung Schwedens letztlich, auf reichsrechtlich-offizieller Ebene - zumindest einer bestimmten Lesart des Vertragstextes nach - als Angehörige der Confessio Augustana bezeichnet sowie akzeptiert zu werden und damit ein Ziel zu erreichen, in dessen Dienst sie seit annähernd 70 Jahren weite Teile ihrer theologischen Publizistik gestellt haben. So wird $1648 \mathrm{im}$ Instrumentum Pacis Osnabrugensis, Artikel VII, § 1 festgelegt, dass die im Religionsfrieden von 1555 festgeschriebenen Rechte für die katholischen ebenso wie für die der Confessio Augustana angehörenden Stände gelten sollen. Dabei werden sie ausdrücklich auch denen zugesprochen, qui inter illos reformati vocantur ${ }^{62}$. Freilich lässt nun die gewählte Formulierung wegen des illos und der damit verbundenen Dissimulation einen gewissen Interpretationsspielraum, ${ }^{63}$ doch kann

62 Instrumentum Pacis Osnabrugensis [künftig: IPO], Art. VII, § 1, in: Acta Pacis Westphalicae, Serie III, Abt. B: Verhandlungsakten, Bd. 1/1: Die Friedensverträge mit Frankreich und Schweden. Urkunden, bearb. v. Antje Oschmann, Münster 1998, 129.

63 Die interpretationsbedürftige Formulierung lautet: Unanimi quoque Caesareae maiestatis omniumque ordinum Imperii consensu placuit, ut quicquid iuris aut beneficii cum omnes aliae constitutiones Imperii tum pax religionis et publica haec transactio in eaque decisio gravaminum caeteris catholicis et Augustanae confessioni addictis statibus et subditis tribuunt, id etiam iis, qui inter illos reformati vocantur, competere debeat salvis tamen semper statuum, qui protestantes nuncupantur, inter se et cum subditis suis conventis pactis, privilegiis, reversalibus et dispositionibus aliis, quibus de religione eiusque exercitio et inde dependentibus cuiusque loci statibus et subditis hucusque provisum est, salva itidem cuiusque conscientiae libertate (IPO, Art. VII, §1, 129). Fritz Dickmann, Der Westfälische Frieden, hg.v. Konrad Repgen, Münster ${ }^{7} 1998,464$ f., erklärt dazu: „Was der Friede den Ständen allgemein, sowohl katholischer wie Augsburgischer Konfession, zubilligte, hieß es da, solle auch denen zustehen, ,die unter jenen Reformierte genannt werden‘. Dieses ,inter illos ‘ ließ sich nach Belieben auf die zuerst genannten Stände allgemein oder auf die zuletzt genannten Stände Augsburgischer Konfession beziehen. Nahm man das zweite an, so waren die Reformierten ausdrücklich zur Confessio Augustana gezählt, entschied man sich aber für das erste, so blieb die Frage offen, es lag dann zwar keine Anerkennung, aber auch keine Verneinung dieser Zugehörigkeit vor. Die Re- 
letztlich daran kein Zweifel bestehen, dass die Deutung, mit jenen Worten würden

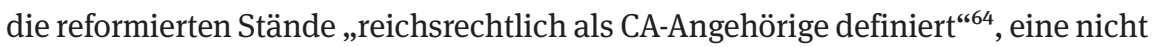
unerhebliche Plausibilität für sich beanspruchen kann. Fortan konnten die Reformierten demnach als juristisch belastbar in die Gruppe der Augsburger Konfessionsverwandten integriert, eben als Augustanae confessioni addicti betrachtet werden. Zwar war die Debatte um die konfessionelle Reichweite der Augsburger Konfessionsverwandtschaft auf theologischer Ebene damit noch längst nicht beendet, im Gegenteil: Der theologisch-dogmatische Schlagabtausch ging munter weiter. Doch delegierte das Osnabrücker Friedensinstrument den Streit von der Ebene des Reiches auf die der Reichsterritorien; reichsrechtlich konnte die Einbeziehung der Reformierten in den Religionsfrieden zur Wahrung der mühsam aufgerichteten Ordnung seit 1648 als erledigt angesehen werden. Daher verlor die Auseinandersetzung angesichts der flächendeckenden Durchsetzung der integrativen Lesart des IPO und aufgrund bestimmter Akzentverschiebungen in der Argumentation weitestgehend ihre rechtlich wie politisch existentiell bedrohliche Dimension für die reformierten Stände auf der Ebene des Reiches. ${ }^{65}$

\section{Abschließende Überlegungen}

Freilich ist mit all dem die innerprotestantische - in diesem Kontext präziser: die zwischen reformierten und lutherischen Theologen über Generationen kontrovers ausgetragene - Debatte um den Anspruch auf Augsburger Konfessionsverwandtschaft und somit auf den Schutz der Friedensbestimmungen von 1555 nur ausschnittweise nachgezeichnet worden. Zudem bildet die skizzierte Auseinandersetzung selbst lediglich ein Diskussionsfeld zwischen den reformatorischen Konfessionskirchentümern im Reich, wenn auch ein diskursiv bemerkenswertes. Denn der den Diskurs begründende und dynamisierende theologische Spannungsreichtum innerhalb der Leitidee der Augsburger Konfessionsverwandtschaft war schon formal bedingt durch die zwei von den konkurrierenden Lagern als Referenztexte aktivierten Versionen der Confessio Augustana bei diesbezüglich mangelnder Festlegung oder - positiv formuliert - gezielter Offenheit des Vertragstextes von 1555. An und mit der Frage nach der reichsrechtlich verbindlichen Bekenntnisversion und der historischen sowie dogmatischen Begründung der je eigenen Antwort wurden letztlich konkurrierende religiöse Wahrheitsansprüche

formierten hatten ,inter hos' gefordert, was die Frage zu ihren Gunsten entschieden hätte; was jetzt vorlag, war ein Kompromiß, die jeder Partei die ihr genehme Auslegung erlaubte (IPO VII §1)“. 64 Hauschild, Die Geltung der Confessio Augustana, $178 \mathrm{f}$.

65 S. dazu Christian Volkmar Witt, Protestanten, 124-58. 
in ihrer ganzen theologischen und juristischen Tragweite gegeneinander ins Feld geführt, die unbenommen aller faktischen konfessionellen Pluralität, mit der es rechtlich umzugehen galt, vorerst jeden Pluralismus als affirmativen Zugang zu jener Pluralität ausschlossen. Vor diesem Hintergrund bedeutete die Inanspruchnahme der Augsburger Konfessionsverwandtschaft durch die eine Seite dogmatisch die Exklusion der anderen, und diese lehrmäßige Exklusion aus der Gemeinschaft der Augsburger Konfessionsverwandten, die eben mit dem Ausschluss aus dem Bereich der Rechtgläubigkeit gleichzusetzen war, zog aufgrund der zeitgenössischen Wahrnehmungsmuster das Damoklesschwert des Ausschlusses aus dem Augsburger Religionsfrieden nach sich. Die damit angerissene Verquickung von Theologie, Politik und Reichsrecht verlieh der Auseinandersetzung der Theologen letztlich ihre Schärfe.

Die um die Augsburger Konfessionsverwandtschaft als theologischem und rechtlichen Zentralbegriff ausgetragene konfessionelle Konkurrenz trug nun allerdings dazu bei, „Modelle der rechtlichen Zähmung von Konflikten sich ausschließender religiöser Wahrheitsansprüche $\mathrm{zu}$ entwickeln" ${ }^{\text {“66, }}$, wie das IPO und die entsprechenden Folgedebatten verdeutlichen. Die religiösen Wahrheitsansprüche und der daraus resultierende theologisch-konfessionelle Streit gefährdeten die mit dem Augsburger Religionsfrieden aufgerichtete Ordnung im Reich, deren Fragilität auch für um die Wahrheit streitende protestantische Theologen außer Frage stand. Kurz: Sie mochten als Anhänger verschiedener reformatorischer Strömungen um den Geltungsbereich des Religionsfriedens streiten; seine prinzipielle Geltung, seine Würde und seinen Wert stellten sie dadurch keineswegs infrage. Vielmehr wurde die schwerlich zu überschätzende Bedeutung des Friedensschlusses von 1555 durch das Ringen um seinen Schutz noch unterstrichen. Die aufgezeigten rechtlichen Einhegungen des Konflikts sind demnach in ihrer Entwicklung nicht unabhängig von den theologischen Debatten zu betrachten und wirkten wiederum in komplexen Zusammenhängen auf die theologischen Diskurse und die dahinterliegenden religiösen Wahrnehmungsmuster zurück, wie diese ihrerseits auf die Rechtsentwicklung wirkten, bis schließlich nach einem langwierigen Prozess des historisch nur schwer zu sortierenden Inund Miteianders beider Felder und in spezifischen mentalitäts-, ideen- und institutionengeschichtlichen Bedingungsgefügen die Kräfte der konfessionellen Unterscheidung und Abgrenzung allmählich abnahmen.

66 Christoph Strohm, Die produktive Kraft konfessioneller Konkurrenz für die Rechtsentwicklung, in: ders. (Hg.), Reformation und Recht. Ein Beitrag zur Kontroverse um die Kulturwirkung der Reformation, Tübingen 2017, 131-71, hier: 160. 
Nun lässt sich über die Schlussfolgerungen aus dem frühneuzeitlichen innerprotestantischen Streit um die Augsburger Konfessionsverwandtschaft und über dessen Orientierungspotential für heutige Ökumenebemühungen zwischen evangelischen Kirchen und katholischer Kirche im Allgemeinen, die ökumenische Arbeit an und mit der Confessio Augustana im Besonderen schon angesichts der historischen Distanz diskutieren. Bedenkens- oder zumindest erinnernswert bleibt jedenfalls dreierlei: Zum einen wird man heute das gegenwärtig oftmals positive Verhältnis zur und Verständnis von Ökumene aufseiten landeskirchlichprotestantischer Gemeinden und Kirchen nicht losgelöst vom mehr oder weniger ausgeprägten Bewusstsein um die Trennung zwischen Reformierten und Lutheranern einerseits, andererseits aber eben auch um die Überwindung dieser Trennung sehen und geschichtlich einordnen können. Diese Überwindung war sicher kein ausschließliches Verdienst protestantischer Theologie, die ohnehin faktisch nur in Wechselwirkung mit anderen Kulturfeldern existierte und sich dessen in ihren gesellschaftsgestaltenden Höhen auch stetig bewusster wurde. Gleichwohl prägte der lange, wechselhafte geschichtliche Weg, den die beiden genannten reformatorischen Kirchentümer gegen- und zugleich miteinander zurückgelegt haben, gerade in und mit seiner theologischen Begleitung die religiöse Selbst- und Fremdwahrnehmung zahlreicher Generationen und setzte schließlich seit der zweiten Hälfte des 18. Jahrhunderts nicht zuletzt dezidiert pluralistische Hermeneutiken aus sich heraus. ${ }^{67}$ Diese Hermeneutiken sollten wesentlich dazu beitragen, dass im 20. Jahrhundert im Rahmen der europaweiten protestantischen Ökumene kirchlich-institutionelle und theologische Konsense erarbeitet werden konnten, die auf der positiven Wahrnehmung konfessioneller Pluralität beruhten. Gedacht ist besonders an die Leuenberger Konkordie.

Damit hängt ein zweiter Punkt unmittelbar zusammen: Die auf Dauer pazifizierende Wirkung konfessioneller Konkurrenz, wie sie um den Anspruch der Augsburger Konfessionsverwandtschaft in der Frühen Neuzeit herrschte, mündete eben nicht in umfassende dogmatische Uniformierung oder anderweitige institutionelle Pluralitätsreduktionen, ganz im Gegenteil: Die spannungsreiche Vielfalt der reformatorischen Kirchen und Theologien blieb als Nebeneinander unterschiedlicher konfessioneller Geltungsansprüche und -behauptungen erhalten und nahm durch das Aufkommen der unierten Landeskirchen und ihrer dezidierten Ablehnung im 19. Jahrhundert sogar noch zu. So kommt das sich konkret

67 Vgl. als illustrierende Fallstudie Christian Volkmar Witt, „... denn Friede ist nur, wo Verschiedenheit ist!“ Historisch-theologische Beobachtungen zum Verhältnis der Konfessionen zwischen Pluralität und Pluralismus, in: Stefan Kopp/Joachim Werz (Hg.), Gebaute Ökumene. Botschaft und Auftrag für das 21. Jahrhundert?, Freiburg i. B. 2018 (Theologie im Dialog 24), $39-57$. 
unterschiedlich ausgestaltende institutionelle Zusammengehen von Reformierten und Lutheranern als Folge der Konkurrenzerfahrung - als Folge der geschichtlichen Erfahrung konfessionellen Streits und seiner Überwindung - und als Ausdruck aufgeklärten religiösen Pluralismus in der Rückschau exemplarisch als Phänomen der konfessionellen Pluralitätssteigerung zu stehen. Nicht zuletzt darin dürfte sich der in der institutionellen Leitidee der Augsburger Konfessionsverwandtschaft verarbeitete Spannungsreichtum empirisch widerspiegeln.

Drittens vermögen die kursorisch vorgestellten vielschichtigen kirchen- und theologiegeschichtlichen Entwicklungen vielleicht insofern auch als Lehrstück für die gegenwärtige theologische Arbeit an der Ökumene $\mathrm{zu}$ dienen, als sie verdeutlichen, dass die Erarbeitung des Gemeinsamen dem Bewusstsein des Trennenden nicht entgegensteht und nicht zwangsläufig im Modus des Bedauerns vorfindlicher Pluralität geschehen muss. Die theologische Auseinandersetzung um die Reichweite des Religionsfriedens entlang der Debatte um die Augsburger Konfessionsverwandtschaft mit all ihren rechtlichen wie religiösen Implikationen, ihre sich geschichtlich verändernde theologische, historische, kirchliche Wahrnehmung, Deutung, Analyse und Einordnung legen doch mindestens nahe, worauf zeitlich wie inhaltlich belastbare Ökumene angewiesen ist: auf die sorgsame, beizeiten sicher auch diskursiv mühsame Identifikation sowie auf die wissenschaftlich gewissenhafte Aufarbeitung der historisch-theologischen und theoretisch-begrifflichen Voraussetzungen, Zusammenhänge und Aneignungen sowohl des Trennenden als auch des Gemeinsamen.

Freilich verweist diese Angewiesenheit, konkret bezogen auf die Denkarbeit mit und an der Confessio Augustana, in einem ersten Schritt auf die Notwendigkeit der historischen Kontextualisierung des Bekenntnisses. Die Confessio Augustana erweist sich dann „dem Kirchenhistoriker [...] als ein durchaus zeitbedingtes und systemgebundenes Dokument, sie breitet ihre Inhalte nicht einfach in freier Darlegung aus, sondern ist durch spezifische Rücksichten gelenkt und gefesselt. Diese Feststellung klingt abschätzig, doch ist sie nicht so gemeint, im Gegenteil: Über den Zeiten schwebende, eine theologia perennis wiedergebende Texte kann sich zumindest der evangelische Theologe nicht vorstellen“68.

68 Bernd Moeller, Das Reich und die Kirche in der frühen Reformationszeit, in: Bernhard Lohse/ Otto Hermann Pesch (Hg.), Das „Augsburger Bekenntnis“ von 1530 damals und heute, München 1980, 17-31, hier: 30. 